\title{
Chapter 5 \\ Lessons from Taking Stock of 12 Years of Swiss International Cooperation on Climate Change
}

\author{
Monika Egger Kissling and Roman Windisch
}

\begin{abstract}
A stronger focus on results achieved in international cooperation on climate change has become common in the Swiss Agency for Development and Cooperation SDC (www.eda.admin.ch/sdc) and the State Secretariat for Economic Affairs SECO (www.seco.admin.ch). In 2014 these agencies have commissioned an assessment on the effectiveness of more than 400 of their climate change interventions over the timeframe of 12 years (2000-2012). This paper presents the methodological approach of the assessment and its results. In a second step and most importantly, it summaries the challenges and lessons learnt of commissioning and conducting such a stock-taking exercise in the field of climate change. These lessons are addressed to evaluators, practitioners and policy makers. In general, the paper concludes that preparing such a report on the effectiveness of the international cooperation in climate change is indeed a very challenging exercise. More specifically, the paper argues that firstly many more efforts are needed from evaluators to identify best methodological practices in dealing with such a mass of information, the wide and highly diverse portfolio and a lack of good quantitative and qualitative data. Secondly, practitioners need to invest more in project design and in monitoring in order to provide accurate data as a basis for sound assessment. Finally, policy makers should be well aware of the significant investments needed for such assessments as an instrument of accountability. This paper thus contributes to the debate among interested stakeholders on the need for better results measurement and results reporting in international cooperation on climate change.
\end{abstract}

\footnotetext{
M. Egger Kissling $(\bowtie)$

Evaluation and Corporate Controlling Division, Swiss Agency for Development and

Cooperation, Berne, Switzerland

e-mail: egger.consulting@bluewin.ch

R. Windisch

Quality and Resources Division WEQA, Swiss State Secretariat for Economic Affairs SECO,

Berne, Switzerland

e-mail: roman.windisch@eda.admin.ch
} 
Keywords Climate change - Swiss International Cooperation - Effectiveness • Measurement and reporting $\bullet$ Lessons

\subsection{Introduction}

A stronger focus on results has become common among international development agencies over the last decade. This is also the case for Switzerland and its two development agencies, the Swiss Agency for Development and Cooperation SDC ${ }^{1}$ (Federal Department of Foreign Affairs) and the State Secretariat for Economic Affairs SECO ${ }^{2}$ (Federal Department of Economic Affairs, Education and Research). For SDC and SECO it is important and of great interest to understand what worked and which interventions were effective, which interventions have not produced tangible results and what the reasons for success or failure are. Consequently, Switzerland regularly produces thematic Reports on the Effectiveness of the Swiss International Cooperation. Following effectiveness reports on Water (2008) and on Agriculture (2010), ${ }^{3}$ the third Report on Effectiveness (2014) was dedicated to Climate Change. Taking stock of results achieved in international cooperation on climate change is a challenging exercise. One has to deal with a mass of information, a broad and highly diverse portfolio and a variety of actors. The consultants had to build on poorly developed methodologies and few internationally recognized standards for measuring climate change adaptation. They were also confronted with the lack of explicit climate baseline data and the difficulties in attributing (and aggregating) the effects of mitigation measures to Swiss interventions. Informing the parliament and the greater public on the results in a synthesized but still relevant manner on the basis of a comprehensive and highly technical report was another demanding task.

The main reason for those significant challenges was the fact that the assessment of the International Cooperation portfolio of 423 climate change relevant projects covering the timeframe 2000-2012, was a pioneer undertaking. Switzerland was one of the first bilateral donors commissioning such an assignment. Consequently, this assessment is of specific originality and can be considered as a pioneer venture of a bilateral donor in putting the climate lens on a longstanding development cooperation portfolio.

The authors' perspective is that of a donor administration. In this chapter the results of the assessment are briefly presented. However, the chapter is mainly focused on the process and presents the lessons of commissioning and conducting the stock taking on 12 years of Swiss International Cooperation on Climate Change. It also presents lessons on how to improve the evaluability of climate change

\footnotetext{
${ }^{1}$ www.deza.admin.ch

${ }^{2}$ www.seco.admin.ch

${ }^{3}$ Available under https://www.eda.admin.ch/deza/de/home/resultate_und_wirkung/wirkungs-_ und_jahresberichte.html and http://www.seco-cooperation.admin.ch/themen/01033/01130/ 05122/index.html?lang=en
} 
relevant programs and maximize climate change effectiveness from a practitioner's perspective. Finally the authors also present related conclusions and lessons learnt for policy makers.

\subsection{Purpose}

The purpose of initiating a "Report on the Effectiveness of the Swiss International Cooperation in Climate Change" was primarily accountability. The report aimed to provide mainly the members of the Swiss Parliament and the interested Swiss public with an accountable and transparent assessment of the climate change relevant interventions financed through public funds in the period 2000-2012. The report further accounts for the use of additional funding for climate change relevant interventions which aimed at raising Swiss ODA contributions to $0.5 \%$ of gross national income (GNI). ${ }^{4}$ These additional Swiss ODA contributions had been classified as Fast Start Financing (FSF) under the United Nations Framework Convention on Climate Change (UNFCCC).

The scope of the evaluation is focusing exclusively on the effectiveness of the portfolio. Thus the assessment is not an evaluation sensu stricto. The other OECDDAC evaluation criteria (relevance, efficiency, impact, sustainability) have not been assessed and the report has not produced any recommendations.

Furthermore, it is important to highlight that the assessment has a clear focus on the climate change effectiveness of the portfolio, rather than assessing its overall results and achievements in relation to poverty alleviation which is regularly scrutinized in other studies and evaluations. Its findings on climate change effectiveness can therefore not be used to imply anything to the over-arching poverty reduction objectives and results of the Swiss International Cooperation. However, the impact of climate change on development is evident. People in developing countries are also more vulnerable to the negative consequences of climate change due to widespread poverty and lower resilience and coping capacities. Therefore, it seems apparent that climate change adaptation and mitigation measures have positive impacts on poor populations.

The evaluation assessed the effectiveness of SDC's/SECO's projects along the following general questions:

- How have climate change relevant interventions achieved their objectives and proven to be successful and effective in terms of mitigation and adaptation?

- To what extent have climate change relevant projects proven to be successful and effective in contributing to a low carbon development in the partner countries?

\footnotetext{
${ }^{4}$ Refer to the message for the increase of funds for the official development aid available under http://www.seco-cooperation.admin.ch/org/00515/00516/index.html?lang=en. This documents is available only in German and French $\times$
} 
- To what extent have climate change relevant projects proven to be successful and effective in contributing to a climate-resilient development in the partner countries?

- What obstacles, difficulties and challenges have undermined the desired success and effectiveness of climate change relevant interventions and which measures were undertaken to address them?

The evaluation was commissioned to Gaia Consulting Oy Ltd, Helsinki/Finland, in consortium with Zoï Environment Network, Geneva/Switzerland and Creatura Ltd, Bath/UK through an open tendering process. The tender document included the task to develop a suitable methodology, using different techniques and tools, which allow for the assessment of the project results and the production of aggregated result statements at portfolio level. Gaia consortium was required to document methodology, assessment, results and conclusions in a fully technical report. The contract included also the production, based on the technical report, of a public report for dissemination, using modern communication techniques, including the production of a video. The consortium was therefore charged to present solid evidence-based results in an attractive manner for different targeted audiences. By reporting on and accounting for the achieved results in Climate Change, the report also contributed to the institutional learning at SDC and SECO.

\subsection{Methodology}

In preparation for the Terms of Reference of the mandate, SDC and SECO had already undertaken some analytical work in order to specify the scope and volume of the assessment. Firstly, every project within the whole portfolio of Swiss International Cooperation was rated ex post on its climate change relevance (the extent to which its main objectives contribute to climate change mitigation and climate change adaptation), resulting in a portfolio of 508 individual, climate change relevant projects. Within this portfolio 283 projects with a total value of CHF 975 million were implemented by SDC, and 140 projects with a total value of CHF 346 million by SECO. A number of these projects were initiated before 2000 , and some projects were still ongoing by the time the evaluation was finished. The total budget of climate change related commitments for this period amounted to CHF 1.32 billion, around $5 \%$ of the overall ODA funding provided by Switzerland during these years. Secondly, the intervention logic on portfolio level was reconstructed, resulting in the definition of seven different result chains defining concrete outputs, outcomes and impacts (see Fig. 5.1).

The intervention logic sets the frame for formulating a theory of change for each of the three areas of interventions (Enabling Framework, Mitigation and Adaptation). They are closely linked to the intended results at outcome/impact level formulated in Fig. 5.1. 


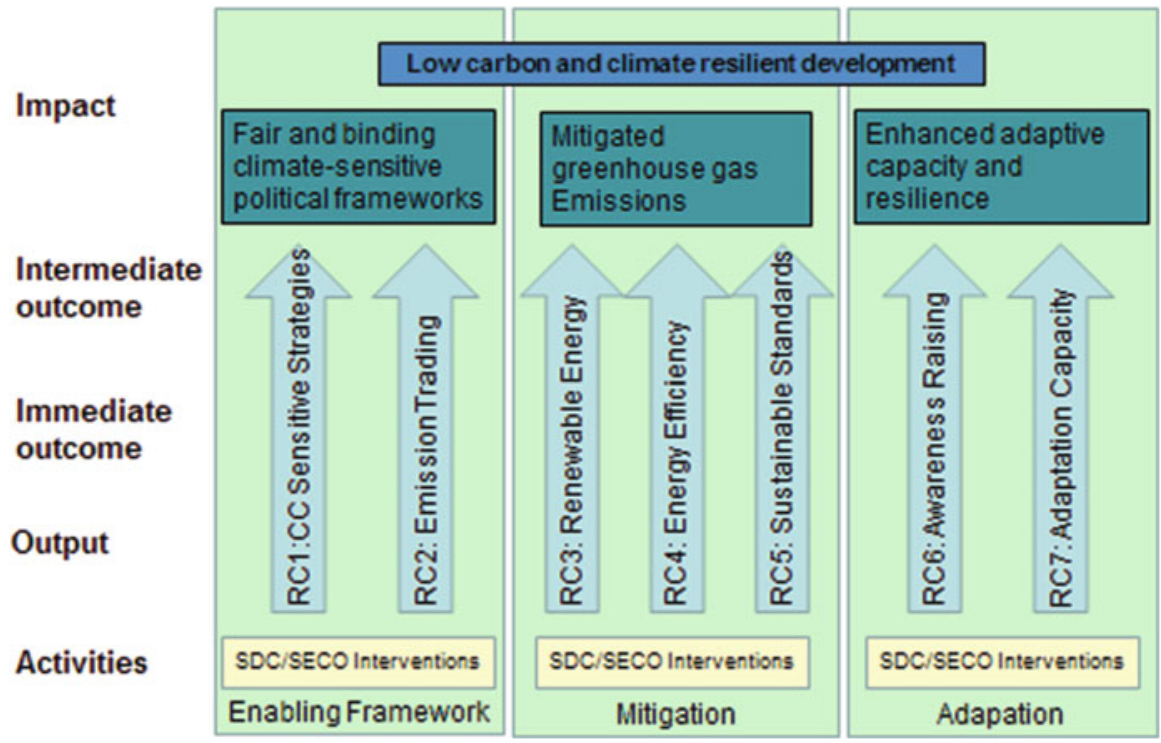

Fig. 5.1 Intervention logic of Swiss International Cooperation in climate change. $R C=$ result chain (Source: SDC/SECO, Tender Document, Report on Effectiveness of the Swiss International Cooperation in climate Change Mitigation and Adaptation Interventions 2000-2012, 2013-04-09, p. 8)

Theory of Change for the Area of Intervention 'Enabling Framework' Switzerland's engagement for Enabling Frameworks contribute to the development of fair and binding climate-sensitive political frameworks on international level and in partner countries. It ensures that negotiations on strategies on growth and development are built on principles of "green and low carbon growth" and on "building climate resilience of systems and people".

\section{Theory of Change for the Area of Intervention 'Climate Change Mitigation'}

Switzerland's engagement for climate change mitigation reduces GHG Emissions in partner countries by facilitating the access and use of low carbon technologies in the production processes and energy systems. It also supports the sustainable use of natural resources through the use of norms and standards as well as best practices in agriculture, forestry and water management. 


\section{Theory of Change for the Area of Intervention 'Climate Change Adaptation'}

Switzerland's engagement for climate change adaptation enhances the adaptive capacity and resilience in partner countries through a combination of interventions allowing to secure and improve living conditions and livelihoods of people affected by climate change.

How the terms are used in the assessment:

- ClimATE CHANGE MITIGATION $=$ Avoiding the unmanageable. Preventing, reducing or avoiding human-made greenhouse gas emissions, for example by promoting renewable energies.

- CLIMATE CHANGE ADAPTATION = Managing the unavoidable. Increasing resilience and capacity to cope with and adapt to the effects of climate change, for example by improving early warning systems for extreme weather events.

Since there is no accepted standard methodology for the summative assessment on portfolio level as requested in the mandate, the consultants applied an innovative and adaptive approach to develop a suitable methodology. The finally applied methodology covered the following three steps:

- Portfolio appraisal: In a first step, the consultants conducted an independent appraisal of the portfolio, reviewing and developing an understanding of the nature of all 508 projects, exploring the quality of available data, validating the proposed climate change relevance of the projects and identifying suitable clusters in reference to the proposed result chains. This resulted in a portfolio of 423 assessable projects, categorized into six thematic clusters (energy, cleaner production, natural resources, hazards, livelihoods, knowledge) and the funding and grants to organizations as a separate cluster. Furthermore six countries including 30 projects (five in each country) were identified for field visits and in-depth studies. The selection had to consider the following criteria:

- Thematic balance: The selected projects had to include and balance interventions in the three Areas of Intervention (Enabling Framework, Adaptation and Mitigation).

- Geographical balance: The selected projects had to include and balance interventions in priority countries from different continents including the former Soviet Republics/countries from Eastern Europe.

- Institutional balance: The selected projects had to include and balance projects of SDC and SECO and reflect bilateral and multi-bilateral funding schemes.

- Performance balance: The selected projects had to represent strengths and weaknesses/successes and challenges of the Swiss International Cooperation in Climate Change.

- Time balance: The selected projects had to represent the whole observation period, considering the increasing relevance of climate change in Swiss International Cooperation over time. 
- A further critical requirement was the availability of an adequate documentation of the selected projects.

- Finally, some projects should have produced visible effects that would allow an attractive visualization of achievements.

- Key questions: The Climate Change Report on Effectiveness investigates the achieved results of the selected 423 climate-relevant projects carried out by the SDC and the SECO in the areas of climate change adaptation and climate change mitigation. The key questions for the analysis were: What contribution did the projects make towards improving people's ability to cope with the negative effects of climate change (adaptation)? What contribution did the projects make towards reducing greenhouse gas emissions (mitigation)? To what extent did Switzerland's engagement for enabling frameworks contribute to the development of fair and binding climate-sensitive political frameworks at the international level and in partner countries?

- Detailed investigations: The second step comprised more detailed investigations of these 30 projects during field visits to the selected six countries (Nepal, South Africa, Peru, Mongolia, Serbia and Albania). The desk study of 31 additional projects (including an in-depth study of projects in Vietnam) ensured the balanced coverage across the various themes and modalities within the portfolio. The project documentation included planning and reporting documents such as Credit Proposals, Annual Reports, Progress Reports as well as Evaluation Reports. The detailed investigations involved direct interviews with knowledge holders at project level.

- Portfolio analysis: The third step was to analyse the complete portfolio of 423 projects, and to determine adaptation and/or mitigation effectiveness scores, with the aim of estimating the overall effectiveness of each thematic approach and of the whole portfolio. This assessment drew on the portfolio appraisal, detailed project reviews, questionnaires, interviews, and focus group discussions. Overall effectiveness scores for the 423 projects for which sufficient information was available were distributed across all themes. These scores were either 'tentative' or 'confirmed' and both represented the reviewer's judgement on the project's effectiveness, from 'extremely strong' (score 7) to 'none'. Tentative scores were based on the information presented in key documents, informed by similar projects that have been reviewed through in-depth assessments, as well as sectoral specific reputation of the implementing partner. Confirmed scores were based on the findings of the 61 detailed desk and field studies, and replaced the tentative scores in each of these cases. The distribution of effectiveness scores in the sample of confirmed scores $(n=61)$ was compared with that in the larger sample of tentative scores $(n=362)$, and the distributions were found to be significantly correlated. Though not as perfect as an in-depth study of all 508 projects would have been, the use of tentative scores in the overall assessment was necessary. The portfolio was far too diverse to yield meaningfully representative results or aggregate results statements for the whole portfolio. 


\subsection{Results}

The assessment concluded that, on average, the 423 projects of Swiss international cooperation analyzed show "moderate to strong" effectiveness in reducing greenhouse gas emissions and in increasing people's ability to cope with the impacts of climate change. Approximately $40 \%$ of the portfolio was found to be strongly or very strongly effective, both in climate change mitigation (114 projects) and adaptation (121 projects). Around $50 \%$ of the total portfolio budget was allocated to interventions assessed as moderately effective (198 projects) in terms of climate mitigation or adaptation. Only $10 \%$ of the projects showed little or no climate benefit.

Despite the geographical and cultural diversity of over 70 partner countries within the portfolio, no difference in effectiveness between the different geographical regions were identified. It has been found that climate effectiveness improved over time, with higher effectiveness scores of projects implemented after 2007. Thus the share of adaptation projects rated as highly and very highly effective increased from 23 to $66 \%$ between the projects implemented in the periods 2000-2006 and 2007-2012. For mitigation, the increase was from 36 to $54 \%$. Furthermore, recent projects in the portfolio integrated climate change more explicitly into project design and the quality of design of these specific interventions improved. Finally, the creation of the SDC Global Programme on Climate Change and the development of a new thematic priority "Fostering climate-friendly growth" in SECO are signs of increased strategic importance and institutional awareness on climate change.

The stock taking exercise did not identify factors of success that are specific for high climate change mitigation or adaption effectiveness. It rather concluded on general success factors such as a comprehensive project design, high stakeholder commitment and ownership, good project management to be a precondition for highly satisfactory results achievement. At the same time, the report identified several domains that proved having predominantly positive results. For mitigation they include the rehabilitation of hydropower plants, improving energy efficiency, promoting renewable energy and cleaner production, and improved ecosystem management. Multi-stakeholder forest management projects, biotrade-based conservation and organic farming projects create in addition to mitigation results, in many cases, also important adaptation benefits. In the adaptation field, Swissfunded interventions in the areas of risk management, disaster risk reduction (including early warning) and insurance are providing real benefits to large numbers of people in various parts of the world. Swiss contributions to several multilateral institutions show high effectiveness overall (both for mitigation and adaptation). For example, the results achieved through the Forest Carbon Partnership Facility (FCPF), the Partnership for Market Readiness and the UNFCCC Adaptation Fund are clearly noted, with Switzerland contributing to the results through its funding alongside expertise and strategic guidance. 


\subsection{Challenges and Lessons Learnt}

\subsubsection{In General}

Preparing such a report on the effectiveness of the international cooperation in climate change is indeed a challenging exercise: one has to deal with a mass of information, with a wide and highly diverse portfolio and with a variety of actors; moreover developing a method for assessing adaption is a crucial challenge. Another demanding task is to inform a larger public on the results presented in a comprehensive and highly technical report in a synthesised but still relevant manner. The elaboration of the report has shown clear limits that must be balanced with too high expectations. Given the lack of comprehensive and reliable data as well as efficient and agreed methodologies to collect quantitative data, mainly in the field of adaption, there is a risk that the results are either too generic at a portfolio level or that "show cases" are reduced to a few examples.

\subsubsection{For Evaluators}

- Resources: The numerous challenges for evaluators in a complex exercise start with the allocation of sufficient resources for such a pioneering assessment. The expectation to conduct a pure accountability exercise in a most efficient way often leads to the allocation of insufficient resources. The absence of welldeveloped methodologies, the huge size of data and information to be assessed in a large portfolio, combined with the expected lack of direct evidence of climate effectiveness has to be taken into account.

- Expectations: The expectations have to be aligned with the size of the investment. The ex-post reconstruction of baselines and the assessment of quantitative results is an intensive and time consuming process. If rigorous climate change related quantitative and qualitative data are not available in final reports or evaluations of the assessed projects, it is illusive to think that an assessment covering a portfolio of several hundred projects is able to fill that gap and to produce aggregated quantitative data, for example on mitigated GHG emissions. When producing data on proxies or qualitative assessments, the expectations must be realistic, not to say modest.

- Independence is one of the most important principles in evaluations focusing on accountability. Ensuring this independence of the consultants in such an innovative approach is however challenging. It could either undermine a constructive exchange between the consultant and the commissioner if implemented too strictly, leaving the consultants too isolated. Or it could lead to in-depth involvement and micro-management by the commissioner especially if there are disparate perceptions on how to approach and address the upcoming challenges in developing the methodology from the very beginning. 
- Scope and focus: The challenges for the consultants in commissioning an assessment with such a narrow scope are twofold. Firstly, consultants might tend to expand their assessment to other OECD DAC evaluation criteria such as relevance, efficiency or sustainability. In particular in a case where the climate change relevant portfolio under review is predefined by the commissioner, the consultants might refuse to accept this climate change earmarking by the mandatory without additional re-verification and assessment.

Secondly, the focus on accountability for effectiveness as well as the renouncement to develop recommendations also demands a clear management of expectations toward the project managers. The intensive involvement of responsible project managers often leads to the expectation that the scope of the assessment can be widen individually and that a report on effectiveness also produces recommendations. The SDC/SECO reports on effectiveness treat learning clearly as a secondary objective and the formulation of recommendations is not part of the evaluation.

- Method: From a clear methodological point of view, the main challenge lies in the late introduction of climate change earmarking SDC and SECO's interventions, the fact that climate change benefits are co-benefits in most projects and that results relevant for accountability toward the public are only achieved with a significant time-lag. Earlier interventions implemented before the introduction of the OECD Rio Markers in 2006 for adaptation and 2010 for mitigation (see References) often do not have an explicit focus on climate change mitigation and adaptation. As a consequence, they often lack clear climate change related objectives, indicators and baselines. Nonetheless, they have potentially produced significant results in terms of climate change mitigation or adaptation and are worth to be included in a report on effectiveness. As mentioned above, the complexity and the resources needed to assess their effectiveness is however much higher in comparison with newer project that have systematically integrated climate change into their results framework (with respective indicators and targets) and consecutive monitoring and evaluation activities.

It is important to notice that the portfolio assessed for this analysis embraced projects and initiatives that were not explicitly making reference to climate change. Initially the projects and programmes implemented mainly during the earlier period were neither fully geared towards nor openly declared as climate change relevant interventions. Only over time, some of them were gradually oriented towards climate change and declared as such. The introduction of the OECD Rio Markers between 2006 and 2010 supported a clear earmarking of climate change relevant projects. Finally the Bill to Parliament on ODA $0.5 \%$ in 2010 specifically earmarked some of its funds to tackle climate change. As a consequence, the precise tracking of climate change relevant interventions was far more difficult for the first half of the period 2000-2012 and many projects had to be classified ex post.

The challenge of time-lag between the implementation of a project and the presence of measurable results at outcome and impact level is particularly relevant for climate change. A report on effectiveness is a very challenging undertaking for a 
topic that is high on the political agenda for a short period only. The results that are of interest for the wider public materialize only with a certain time lag and are not available with the first 3-5 years of a project. In fact, more time between the intervention and the evaluation would be needed in order to assess whether the adaptation measures have been effective and contributed to increased resilience, or whether mitigation measures finally resulted in the expected reduction of greenhouse gas emissions. This also leads to the question if a highly diverse portfolio covering a timeframe of 12 years can be assessed with the same methodology.

Finally the methodological challenges to assess effectiveness also depend on the topic. For adaptation interventions they are considerably higher than for those projects in the field of mitigation. Contrary to the field of mitigation, no clear metric and reliable baseline data exist for measuring adaptation and a lot of the measures are rather more of a qualitative than quantitative nature. Therefore, it is more difficult to find adequate indicators, which can measure effectiveness of the interventions. Thus, more time needs to be invested in the development of baselines and measurement, reporting, and verification systems. Moreover, aggregating and scoring will remain difficult.

Finally the influence and effectiveness of projects working on the policy level to create a better climate change framework is difficult to measure. The assessment concentrated here on interviews with Swiss experts engaged in policy dialogue in international institutions and initiatives and on the institutions' results reporting.

\subsubsection{For Practitioners/Program Managers}

- Results reporting: As in other areas of intervention, the common difficulties in assessing results statements at outcome and impact level have been experienced in the climate change assessment. It revealed several lessons in term of Result Based Management (RBM) and monitoring for project managers of climate change relevant project. Despite the fact that the reorganization process of SDC (2008-2012) has focused on result orientation and that results based management within SECO has been improved, it appears still premature to expect comprehensive and well-documented result reporting on all interventions. This is especially the case for the earlier projects under review. Given the fact that the design of projects in terms of climate change has improved significantly over time, it can be expected that a similar assessment in a few years would be more successful in gathering quantitative and qualitative results, thus allowing for an aggregation at higher level. However, this depends on the development of result frameworks with smart and standardized indicators across the portfolio. Consequent baseline studies and the onset and rigorous monitoring during implementation are further preconditions.

This does not mean that gathering results on climate change effectiveness will become an easy task. The above-mentioned measures need significant resources. Consequently the expectation on a quantitative monitoring of GHG emission 
reductions needs to be clarified explicitly at the beginning of each project. Moreover, if there is a real demand for clear results on portfolio level, the investments in RBM and M\&E need to be approved in order to set the ground for reports on effectiveness that assess results based on evidence.

- Mainstreaming: Although the OECD Rio markers have obliged project developers to systematically consider climate change relevance and benefit within their project, there is further need for more systematic mainstreaming of climate change adaptation and mitigation into development projects. Explicitly mentioning the climate change components and objectives does potentially increase the awareness and ownership at the level of implementing partners, stakeholders and beneficiaries which will positively contribute to the effectiveness of the programs.

- Common understanding: A common understanding between donors and implementing partners on the relevance of climate change within a project is crucial in order to ensure transparent reporting on achieved results. Many donors have been criticized in the past for not applying the Rio markers, in particular the climate-related ones, in a coherent manner. In the framework of this results assessment, Switzerland has conducted an exhaustive revision, has gained a valuable overview and improved its skills in reliable coding of its climate change portfolio.

- Synergies between adaptation and mitigation: The tender document initially proposed a clear separation between a climate change mitigation and adaptation portfolio. The assessment revealed, however, that climate change adaptation and mitigation are often interlinked. A clear separation does miss potential synergies. One should try to reach for multipurpose results in the design of the projects. The report therefore encourages a systematic integration of climate change adaptation into development as a more promising approach in order to achieve sustainable and resilient development, instead of trying to clearly identify "additionality" of adaptation actions. Adaptation and mitigation synergies could be increased, in particular in the natural resource management sector, but also e.g. in hydropower, by addressing the issues more systematically during planning and establishing the adequate measurement, reporting and verification (MRV) systems.

\subsubsection{For Policy Makers}

- Joint forces for better cost-benefit: Policy makers should be better informed on the investment needed for producing reports on effectiveness and be aware about the difficulties and challenges in terms of quality, accessibility and availability of data and the development of adequate methods. A discussion on the need for rigorous results measurement on the "end" side and in consequence the need to invest in rigorous results planning systems on the "entry" side mainly raises questions on priorities and resources (human, financial, time). National 
parliaments could think about joining forces with other donors for initiating joint results assessments on selected topics of the international cooperation in order to have a better cost-benefit-balance and benefit from mutual learning.

- International debate: With regard to international commitments to a global climate deal (Paris 2015) it is critical to sharpen the international understanding on the results measurement related to climate change sensitive investments and to decide on the level of ambition. Strengthening the climate change capacity (policy, planning, and programming) in partner countries are also one precondition to achieve mutual accountability in this sector.

- Swiss CC know-how for development: For climate targeted projects, SDC and SECO could focus/concentrate even more on areas where Switzerland has proven technical expertise, such as renewable energy (in particular hydropower), disaster risk reduction and disaster risk/weather insurance, energy efficiency in buildings and small and medium enterprises, air quality, and ecosystem management.

\subsection{Conclusions}

Based on the experience from this pioneering assessment the key conclusions from the donor's perspective are the following:

- Be precise in the terms and methods: Clearly say what is meant by effectiveness and what the results are about. Avoid vague terms such as "climate benefit" or "climate effectiveness".

- It is difficult to isolate the effect of a single donor's intervention in mitigation. The attribution of climate change projects in the field of mitigation to a single bilateral donor is methodologically questionable, especially without clear baseline data.

- In the field of climate change adaptation quantitative data are often lacking and it is important to appreciate qualitative data in an adequate manner.

- It is difficult to report on policy influencing at international and regional level and to link the effects from being at the table of negotiations with concrete changes in people's life.

The overall conclusion is that this pioneering undertaking of producing the Report on Effectiveness in Climate Change did not allow identifying best methodological practices how best taking stock of climate change projects and programs. This chapter is much more an appeal to be precise, realistic, authentic and transparent in the communication of the methodological challenges and of the results. Let's take the reports on effectiveness as a chance to enter into an open dialog with interested stakeholders, mainly with the national parliament. Let us explore the opportunity and utility to undertake effectiveness assessments jointly with other development agencies and join forces and resources for further improving the approach, the methods and the common learning from effectiveness reports. 


\section{References}

Documents available on the "Report on the Effectiveness of the Swiss International Cooperation in Climate Change":

Swiss Development Cooperation, Swiss State Secretariat for Economic Affairs. (2014). Report on Effectiveness 2014: Swiss International Cooperation in Climate Change 2000-2012. http:// www.seco-cooperation.admin.ch/themen/01033/01130/05122/index.html?lang=en. Accessed 29 Apr 2016.

Information on the legal basis and federal decisions for Swiss International Cooperation available under:

The Swiss Confederation. (2010). Message concernant l'augmentation des moyens pour le financement de l'aide publique au développement. http://www.seco-cooperation.admin.ch/org/ 00515/00516/index.html?lang=en. Accessed 29 Apr 2016.

Documentation on SDC/SECO accountability reports/reports on effectiveness available:

Swiss Development Cooperation, Swiss State Secretariat for Economic Affairs. (2008). Report on the effectiveness of Swiss development cooperation in the water sector. http://www.secocooperation.admin.ch/themen/01033/01130/05122/index.html?lang=en. Accessed 29 Apr 2016.

Open Access This chapter is distributed under the terms of the Creative Commons AttributionNonCommercial 4.0 International License (http://creativecommons.org/licenses/by-nc/4.0/), which permits any noncommercial use, duplication, adaptation, distribution and reproduction in any medium or format, as long as you give appropriate credit to the original author(s) and the source, provide a link to the Creative Commons license and indicate if changes were made.

The images or other third party material in this chapter are included in the work's Creative Commons license, unless indicated otherwise in the credit line; if such material is not included in the work's Creative Commons license and the respective action is not permitted by statutory regulation, users will need to obtain permission from the license holder to duplicate, adapt or reproduce the material.

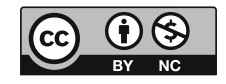

